\title{
Evaluation of pregnant women admitted to Dokuz Eylül University Teratogenicity Information Service due to use of medications affecting the cardiovascular system
}

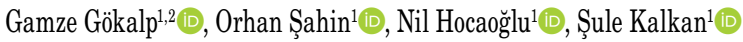 \\ ${ }^{1}$ Department of Medical Pharmacology, Dokuz Eylül University, School of Medicine, Izmir, Turkey \\ ${ }^{2}$ Department of Pediatrics, Division of Pediatric Emergency, Izmir Katip Çelebi University, Izmir, Turkey \\ Received: December 25, 2020 Accepted: January 13, 2021 Published online: March 29, 2021
}

\begin{abstract}
Objectives: This study aims to evaluate the demographic characteristics, maternal and neonatal outcomes of pregnant women receiving cardiovascular medications (CVMs) during pregnancy and admitted to the Teratogenicity Information Service (TIS).

Patients and methods: In this descriptive, cross-sectional, retrospective study, a total of 47 pregnant women (mean age: $34.0 \pm 5.5$ years; range, 19 to 41 years) who were admitted to the TIS of Dokuz Eylul University were included between January 2014 and December 2016. Demographic characteristics, types of the CVMs, concomitant medication and/or substance use, medical and obstetric histories of cases, and maternal and neonatal outcomes were evaluated.

Results: The most commonly used drugs were beta-receptor antagonists. The mean gestational age at the time of delivery was $35.9 \pm 8.2$ weeks and 42 infants (89.4\%) were healthy. Five pregnancies (10.6\%) ended in miscarriage or elective termination. No malformation was found in healthy live newborns.

Conclusion: The use of CVMs during pregnancy remains as a challenging issue, as their potential effects on the developing fetus are not fully known. Based on these study results, it is difficult to determine safety of CVMs during pregnancy and establish a causal relationship between maternal/neonatal outcomes and CVMs exposure.
\end{abstract}

Keywords: Cardiovascular system medicines, maternal and neonatal outcomes, pregnancy.

The use of medications during pregnancy is a common problem across the globe. In $80 \%$ of all pregnancies, prescription or non-prescription medications are used. ${ }^{[1]}$ It has been estimated that malformation affects one to three in every hundred babies, and teratogenic drugs/substances can be only held responsible for less than $10 \%$ of these malformations. ${ }^{[2,3]}$

In developed countries, cardiac diseases are the most common causes of maternal mortality during pregnancy. According to the epidemiological studies, approximately every year $0.2 \%$ of all pregnant women die from cardiac reasons. ${ }^{[1-4]}$ Additionally, in the United States, $11 \%$ of the maternal deaths during pregnancy are caused by cardiac diseases. ${ }^{[5]}$ Physiological changes in pregnancy may adversely affect the prognosis of an existing cardiovascular disease and may alter the effects of medications which affect the cardiovascular system. Also, the effects of the cardiovascular medications (CVMs) on the fetus are not fully known. It is also an undeniable fact that ethical concerns limit the controlled studies on this subject. Thus, the data regarding the use of CVMs during pregnancy and their effect on pregnancy outcomes are limited in Turkey.

In the present study, we aimed to evaluate the demographic characteristics of pregnant women referred to the Teratogenicity Information Service (TIS) during pregnancy and to identify the characteristics of the CVMs exposures and the pregnancy outcomes.

\section{PATIENTS AND METHODS}

This descriptive, cross-sectional, retrospective study was conducted at Dokuz Eylul University, TIS

Corresponding author: Gamze Gökalp, MD. Dokuz Eylül Üniversitesi Tıp Fakültesi, Tibbi Farmakoloji Anabilim Dal, 35220 Balçova, İzmir, Türkiye. Tel: +90 232 - 46969 69 / 3770 e-mail: drgamzegokalp@gmail.com

Citation:

Gökalp G, Şahin 0, Hocaoğlu N, Kalkan Ş. Evaluation of pregnant women admitted to Dokuz Eylul University Teratogenicity Information Service due to use of medications affecting the cardiovascular system. Cardiovasc Surg Int 2021;8(1):20-27. 
between January 2014 and December 2016. Initially, a total of 491 pregnant women were admitted to the TIS for teratogenicity risk evaluation and $62(12.6 \%)$ of these admissions were due to the use of CVMs during pregnancy. Fifteen cases with missing data were excluded from the study. Finally, a total of 47 pregnant women (mean age: $34.0 \pm 5.5$ years; range, 19 to 41 years) were included in the study. Participants who exposed to CVMs alone and together with the other medicines and/or substances were also evaluated. A written informed consent was obtained from each participant. The study protocol was approved by the Dokuz Eylul University, Faculty of Medicine, Non-Interventional Research Ethics Committee (No: 3494-GOA/2017). The study was conducted in accordance with the principles of the Declaration of Helsinki.
The data of the pregnant women included in the study were obtained from the registration forms filled out during the initial admission to TIS. The data collected from the registration forms were as follows: demographic data (age, educational status, presence of consanguineous marriage), medical, family and obstetric history (gestational week, last menstrual period, number of pregnancies, number of live/stillbirths in previous pregnancies, presence of anomalies in previous pregnancies), and CVMs and exposure characteristics (name, content, dose, total amount, and duration). The gestational week was calculated according to the ultrasound data or the last menstrual period. To obtain the verbal consent and investigate the pregnancy outcomes and confirm the data, a phone interview was conducted with each mother. In addition, data related to the

\begin{tabular}{|c|c|c|c|}
\hline Maternal demograph & tetric & acteristics & \\
\hline & $\mathrm{n}$ & $\%$ & Mean \pm SD \\
\hline Gestational age at admission (week) & & & $9.2 \pm 4.7$ \\
\hline Age (year) & & & \\
\hline$\leq 35$ & 21 & 44.7 & \\
\hline$>35$ & 26 & 55.3 & \\
\hline Consanguineous marriage & & & \\
\hline $2^{\text {nd }}$ degree & 2 & 4.3 & \\
\hline $3^{\text {rd }}$ degree & 1 & 2.1 & \\
\hline None & 44 & 93.6 & \\
\hline Maternal education status & & & \\
\hline None & 3 & 6.4 & \\
\hline Primary/secondary school & 25 & 53.2 & \\
\hline High school/university & 19 & 40.4 & \\
\hline Substance/illicit drug use & & & \\
\hline Smoking & 10 & 21.3 & \\
\hline Alcohol & 4 & 8.5 & \\
\hline None & 33 & 70.2 & \\
\hline Radiation exposure & & & \\
\hline Direct graph & 10 & 21.3 & \\
\hline $\mathrm{CT}$ & 1 & 2.1 & \\
\hline None & 35 & 76.6 & \\
\hline Gravidities/parities & & & \\
\hline 1 & 9/11 & $19.1 / 23.4$ & \\
\hline 2 & $18 / 32$ & $38.3 / 68.1$ & \\
\hline 3 and more & $20 / 4$ & $42.6 / 8.5$ & \\
\hline Previous miscarriages/elective termin & & & \\
\hline 0 & 30 & 63.8 & \\
\hline $1-2$ & 15 & 31.9 & \\
\hline 3 and more & 2 & 4.3 & \\
\hline
\end{tabular}


pregnancy outcomes (term birth, preterm delivery, miscarriage, elective termination, stillbirth, baby healthy, presence/absence of anomaly) and possible complications during pregnancy were obtained by phone interviews. Pregnant women who did not give a verbal consent were excluded from the study. Pregnancy outcomes were classified using the International Classification of Diseases $10^{\text {th }}$ revision (ICD 10) definitions of World Health Organization (WHO). ${ }^{[6]}$ Elective termination was defined as the voluntary abortion, miscarriage as a pregnancy loss before 22 completed weeks of gestational age, stillbirth as the birth with no signs of life after 22 completed weeks of gestational age, and preterm birth was defined as the birth before 37 completed weeks of gestational age. ${ }^{[6]}$

\section{Statistical analysis}

Statistical analysis was performed using the IBM SPSS for Windows version 22.0 software (IBM Corp., Armonk, NY, USA). Descriptive data were expressed in mean \pm standard deviation (SD) or median (min-max) for continuous variables and in number and frequency for categorical variables. In the comparison of the two groups, the chi-square $\left(\chi^{2}\right)$ test was used for categorical data. The Fisher's exact test was used, when the $\chi^{2}$ assumption was not met. A $p$ value of $<0.05$ was considered statistically significant.

\section{RESULTS}

Of the patients, the mean gestational age at the time of admission to the TIS was $9.2 \pm 4.7$ (range, 5 to 25 )

\begin{tabular}{|c|c|c|c|c|c|c|c|}
\hline \multicolumn{8}{|c|}{$\begin{array}{c}\text { Table } 2 \\
\text { The association between some properties of pregnants and pregnancy outcomes }\end{array}$} \\
\hline & \multicolumn{6}{|c|}{ Pregnancy outcomes } & \multirow[b]{3}{*}{$p$} \\
\hline & \multicolumn{2}{|c|}{ Healthy birth } & \multicolumn{2}{|c|}{ Abortus } & \multicolumn{2}{|c|}{ Total } & \\
\hline & $\mathrm{n}$ & $\%$ & $\mathrm{n}$ & $\%$ & $\mathrm{n}$ & $\%$ & \\
\hline \multicolumn{8}{|c|}{ Having a baby with anomalies in previous pregnancies } \\
\hline No & 40 & 90.9 & 4 & 9.1 & 44 & 100 & \multirow{2}{*}{0.29} \\
\hline Yes & 2 & 66.7 & 1 & 33.3 & 3 & 100 & \\
\hline \multicolumn{8}{|l|}{ Maternal age (year) } \\
\hline$\leq 35$ & 20 & 95 & 1 & 5 & 21 & 100 & \multirow{2}{*}{0.3} \\
\hline$>35$ & 22 & 84.6 & 4 & 15.4 & 26 & 100 & \\
\hline \multicolumn{8}{|l|}{ Consanguineous marriage status } \\
\hline No & 40 & 90.9 & 4 & 9.1 & 44 & & \multirow{3}{*}{0.70} \\
\hline $2^{\text {nd }}$ degree & 2 & 100 & - & - & 2 & 100 & \\
\hline $3^{\text {rd }}$ degree & - & - & 1 & 100 & & 100 & \\
\hline \multicolumn{8}{|l|}{ Substance use } \\
\hline No & 28 & 84.8 & 5 & 15.2 & 33 & 100 & \multirow{3}{*}{0.16} \\
\hline Cigarette & 10 & 100 & - & - & 10 & 100 & \\
\hline Alcohol & 4 & 100 & - & - & 4 & 100 & \\
\hline \multicolumn{8}{|l|}{ Radiological examination } \\
\hline No & 30 & 85.7 & 5 & 14.3 & 35 & 100 & \multirow{4}{*}{0.23} \\
\hline Direct graph & 10 & 100 & - & - & 10 & 100 & \\
\hline Computed tomography & 1 & 100 & - & - & 1 & 100 & \\
\hline Magnetic resonance imaging & 1 & 100 & - & - & 1 & 100 & \\
\hline \multicolumn{8}{|l|}{ Education status } \\
\hline None & 1 & 100 & - & - & 1 & 100 & \multirow{3}{*}{0.62} \\
\hline Primary/secondary school & 25 & 92.6 & 2 & 7.4 & 27 & 100 & \\
\hline High school/above & 16 & 84.2 & 3 & 15.8 & 19 & 100 & \\
\hline
\end{tabular}


weeks. The rate of consanguineous marriage was $6.4 \%$ $(n=3)$. The maternal and obstetric characteristics are summarized in Table 1.

There was no significant relationship between the presence of consanguineous marriage and pregnancy outcomes $\left(\chi^{2}=0.199, p=0.655\right)$ (Table 2$)$.

When the presence of chronic disease was evaluated, it was found that $89.4 \%(n=42)$ of pregnant women had an existed chronic disease and the most commons were hypertension (HT, 28\%), diabetes mellitus (DM) and hypothyroidism (11.9\%, Figure 1). No statistically significant relationship between presence of a chronic disease and pregnancy outcomes was found $\left(\chi^{2}=0.032\right.$, $\mathrm{p}=0.858)$ (Table 2). The characteristics of illicit drug/alcohol use, radiation exposure or smoking are presented in Table 1.

Approximately one third of pregnant women $(29.8 \%, n=14)$ used CVMs alone and 70.2\% ( $n=33)$ reported concomitant medicine exposures (Table 3). The most frequently exposed concomitant medicines were central nervous system drugs (30.3\%) and analgesics (18.2\%). The proportion of the mothers who used only one group of CVMs and more than one group CVMs were $76.6 \% \quad(n=36)$ and $23.4 \%$ $(\mathrm{n}=11)$, respectively (Table 3$)$. There was no significant difference between using one or more than one group of CVMs and pregnancy outcomes $\left(\chi^{2}=2.787, \mathrm{p}=0.095\right)$.
The most frequently exposed CVMs were beta adrenergic receptor antagonists (beta-blockers), diuretics, angiotensin converting enzyme (ACE) inhibitors, calcium channel blockers (CCB), angiotensin receptor blockers (ARB), antiaggregants, antilipidemics and antiarrhythmics (Table 2). There was no statistically significant difference between groups of CVMs exposed during pregnancy and the termination of pregnancies $(\mathrm{p}>0.05)$.

When gestational outcomes were examined, the mean gestational week at delivery was $35.9 \pm 8.2$ weeks. Of all 47 pregnancies with CVMs exposure, 42 (89.4\%) pregnancies resulted in live births. Three (6.4\%) pregnancies ended in elective termination and two (4.3\%) pregnancies ended in miscarriage (Table 4). No malformation was detected in any of the live births. Neonatal jaundice developed in four (9.8\%) infants and one $(2.1 \%)$ infant needed incubator care.

There was no statistically significant difference between pregnancy outcome and educational status, substance use of radiation exposure during pregnancy ( $p>0.05)$. It is stated that while the $21(44.7 \%)$ pregnant women's age was under 35 years, the $26(55.3 \%)$ pregnant women's age was over 35 years. There was no significant difference between maternal age and the termination of pregnancies $\left(\chi^{2}=0.140, p=0.308\right)$ (Table 2).

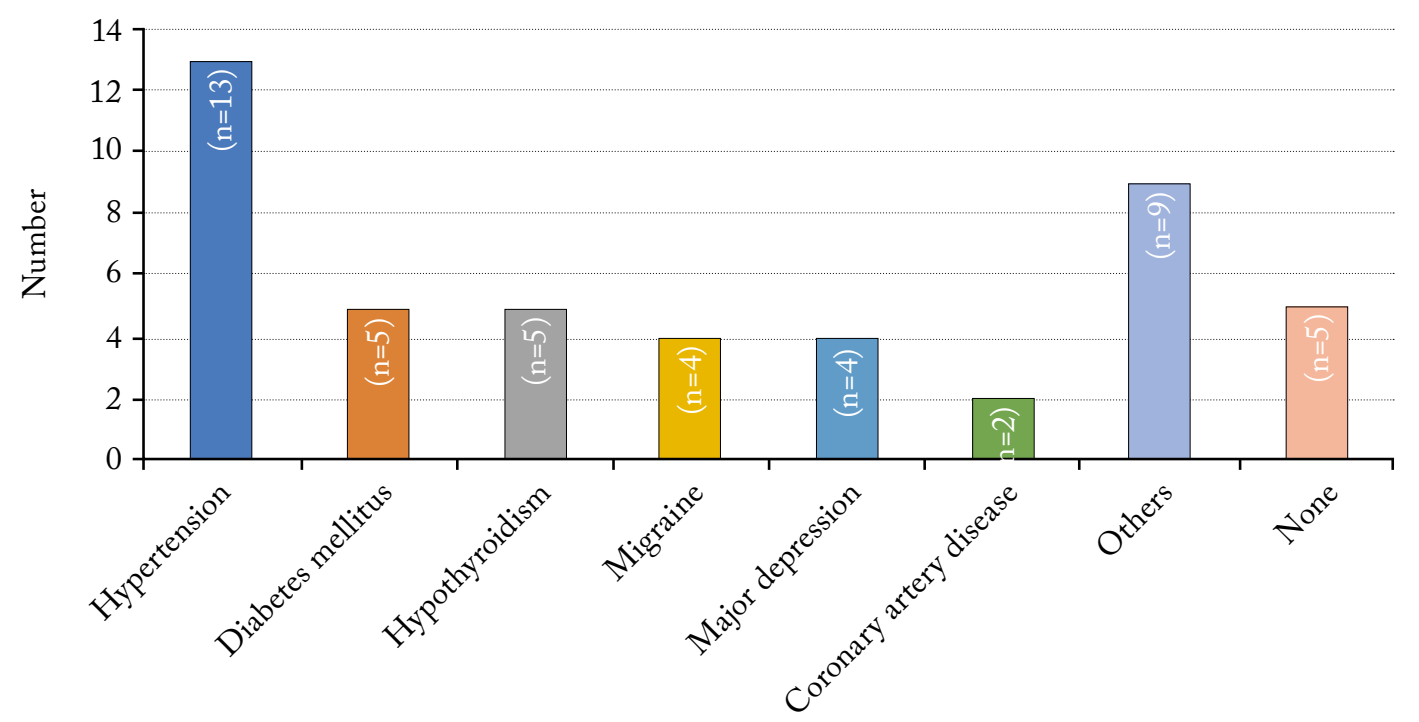

Figure 1. Chronic diseases of the pregnants. 


\begin{tabular}{|c|c|c|}
\hline \multicolumn{3}{|c|}{$\begin{array}{c}\text { Table } 3 \\
\text { Distribution of the medication exposures }\end{array}$} \\
\hline Groups of the medicines & $\mathrm{n}$ & $\%$ \\
\hline Cardiovascular system medicines (CVSMs)* & 55 & 100.0 \\
\hline Beta blockers & 24 & 43.6 \\
\hline Diuretics & 7 & 12.7 \\
\hline Angiotensin converting enzyme (ACE) inhibitors & 6 & 10.9 \\
\hline Calcium channel blockers & 5 & 9.0 \\
\hline Angiotensin receptor blockers (ARBs) & 4 & 7.3 \\
\hline Antiarrhythmic & 3 & 5.5 \\
\hline Antiaggregants & 3 & 5.5 \\
\hline Hypolipidemics & 3 & 5.5 \\
\hline Only one group CVSM exposure** & 36 & 76.6 \\
\hline More than one group CVSM exposure** & 11 & 23.4 \\
\hline Concomitant medicines ${ }^{* * *}$ & 33 & 100.0 \\
\hline Central nervous system medicines & 10 & 30.3 \\
\hline Analgesics & 6 & 18.2 \\
\hline Antidiabetics & 5 & 15.2 \\
\hline Antibiotics & 3 & 9.1 \\
\hline Others & 9 & 27.2 \\
\hline $\begin{array}{l}\text { CVMs: Cardiovascular medications; * Percentages are based o } \\
\text { ** Percentages are based on the total number (47) of pregnants; } \\
\text { number (33) of concomitant medicines. }\end{array}$ & & $\begin{array}{l}\text { of CVMs; } \\
\text { in the total }\end{array}$ \\
\hline
\end{tabular}

\begin{tabular}{|c|c|c|c|c|c|}
\hline \multicolumn{6}{|c|}{$\begin{array}{c}\text { Table } 4 \\
\text { Properties of the cases ended in miscarriage or elective termination }\end{array}$} \\
\hline & Case 11 & Case 17 & Case 24 & Case 36 & Case 41 \\
\hline Age (year) & 39 & 36 & 40 & 36 & 31 \\
\hline Gestational week & 7 & 8 & 6 & 5 & 8 \\
\hline Chronic disease & $\begin{array}{c}\text { Yes } \\
\text { (Hypothyroidism) }\end{array}$ & $\begin{array}{l}\text { Yes } \\
(\mathrm{DM})\end{array}$ & None & $\begin{array}{l}\text { Yes } \\
\text { (Hyperthyroidism) }\end{array}$ & None \\
\hline $\begin{array}{l}\text { Presence of birth } \\
\text { defect in recent } \\
\text { pregnancies }\end{array}$ & None & None & None & None & Yes \\
\hline $\begin{array}{l}\text { Consanguineous } \\
\text { marriage }\end{array}$ & None & $\begin{array}{c}\text { Yes } \\
\left(3^{\text {rd }} \text { degree }\right)\end{array}$ & None & None & None \\
\hline $\begin{array}{l}\text { Substance/illicit } \\
\text { drug use }\end{array}$ & None & None & None & None & None \\
\hline Radiation exposure & None & None & None & None & None \\
\hline $\begin{array}{l}\text { Miscarriage or } \\
\text { elective } \\
\text { termination }\end{array}$ & Miscarriage & $\begin{array}{l}\text { Elective } \\
\text { termination }\end{array}$ & $\begin{array}{l}\text { Elective } \\
\text { termination }\end{array}$ & $\begin{array}{l}\text { Elective } \\
\text { termination }\end{array}$ & Miscarriage \\
\hline Used CVSMs & $\begin{array}{l}\text { Metoprolol, } \\
\text { spironolakton, } \\
\text { amiodarone }\end{array}$ & $\begin{array}{l}\text { Fosinopril } \\
\text { sodium }\end{array}$ & Metoprolol & $\begin{array}{l}\text { Metoprolol, } \\
\text { diltiazem }\end{array}$ & Nebivolol \\
\hline $\begin{array}{l}\text { Concomitant } \\
\text { medications }\end{array}$ & None & $\begin{array}{l}\text { Metformin } \\
\text { hydrochloride, } \\
\text { noretisterone }\end{array}$ & $\begin{array}{l}\text { Hydroxyzine } \\
\text { hydrochloride }\end{array}$ & $\begin{array}{l}\text { Benzathine } \\
\text { benzylpenicillin, } \\
\text { acetylsalicylic acid }\end{array}$ & $\begin{array}{c}\text { Duloxetine } \\
\text { hydrochloride }\end{array}$ \\
\hline
\end{tabular}




\section{DISCUSSION}

In this study, the demographic characteristics of the pregnant women and pregnancy outcomes who exposed to CVMs during their pregnancies were examined. Although most of the pregnancies resulted healthy live births, two (4.3\%) pregnancies ended in miscarriage and three (6.4\%) pregnancies were terminated electively. The rates of miscarriage and elective termination in this study are similar to the general population. ${ }^{[7,8]}$

Cardiac diseases are complicated by approximately $1 \%$ of all pregnancies. ${ }^{[9]}$ Pregnant women with or without underlying cardiovascular disease may need to use CVMs due to the physiological changes during pregnancy. This need may be caused by worsening of an existing disease or by a newly developing condition. In general, medications used to treat cardiovascular conditions are antihypertensives, diuretics, antiarrhythmics, anticoagulants and antilipidemics. Moreover, CVMs are preferred in other indications such as migraine, tremor, hyperthyroidism, and anxiety disorders. ${ }^{[9]}$ However, the effects of CVMs on the developing fetus have not been fully understood, yet. Pregnant women need a careful assessment and counselling for CVMs use and their maternal/fetal effects, as well as expert cardiac care in pregnancy. Teratogenicity Information Services are specialized units providing information on the use of medication/ substance during pregnancy and lactation period. The TIS of Dokuz Eylul University is a regional unit dedicated to provide information about medication/ substance use during pregnancy and/or lactation period since 2011.

Epidemiological data on CVMs exposures during pregnancy are limited. In a study carried out in Germany on drug prescriptions in pregnancy, CVMs accounted for $17 \%$ of the medicines prescribed during pregnancy ${ }^{[10]}$ In another study conducted by Demir et al., ${ }^{[11]} \mathrm{CVM}$ s were responsible for $9.5 \%$ of all exposures among the pregnant women admitted to TIS. Göker et al. $^{[12]}$ also reported that the use of CVM ratios were $1.14 \%$ and $8.17 \%$ in a study evaluating pregnants admitted to two reference hospital in our country. In this study, this rate was $12.6 \%$ of the patients applied to the TIS of our institution.

The increasing prevalence of women with adverse pregnancy outcomes (stillbirth, fetal malformations or abortus) due to the increasing maternal age of first pregnancy remains as a challenging issue. Advanced maternal age, particularly over 35 years of age, poses a greater risk of pregnancy complications. ${ }^{[13]}$ Almost $7 \%$ of stillbirths are attributed to advanced maternal age ( $>35$ years) worldwide. Also, adolescent pregnancy ( $<16$ years) is associated with an increased risk of adverse pregnancy outcomes. ${ }^{[1,14]}$ In this study, the mean age of pregnant women was $34.0 \pm 5.5$ years. Additionally, it is noteworthy that four (80\%) of five pregnancies ended in miscarriage or elective termination were older than 35 years old (31 to 40 years).

The pregnancy termination rates in consanguineous marriages may be higher due to the increased risk for recessively inherited congenital diseases. ${ }^{[14]}$ In a study carried out in our country, the rate of consanguineous marriage was found to be $12.7 \% .{ }^{[11]}$ In this study, the rate of consanguineous marriage was found as $6.4 \%$ and all pregnancies with consanguineous marriages resulted in a healthy infant.

On the other hand, the presence of chronic diseases during pregnancy also poses a risk for adverse pregnancy outcomes. The most common chronic diseases in pregnant women are epilepsy, hypertension, diabetes mellitus, psychiatric diseases, and thyroid dysfunctions. ${ }^{[15]}$ In this study, approximately $90 \%$ of the mothers had a chronic disease, consistent with the previous reports, and hypertension, diabetes mellitus, and hypothyroidism were the most common diseases. Furthermore, $60 \%$ of the mothers whose pregnancies ended in miscarriage or terminated electively had an underlying maternal chronic disease such as hypothyroidism, hypertension, or diabetes mellitus.

Beta-blockers are the most commonly used drugs in the treatment of hypertension in pregnancy and are also frequently used in the management of conditions, such as thyrotoxicosis, hypertrophic cardiomyopathy, and mitral stenosis. ${ }^{[16-19]}$ In this study, in line with the previous reports, the most commonly used CVMs during pregnancy were betablockers, diuretics, angiotensin-converting enzyme inhibitors, calcium channel blockers, and angiotensin receptor blockers, respectively. In addition, $80 \%$ of the mothers whose pregnancies ended in miscarriage or elective termination used beta-blockers. Beta-blockers can cross the placenta and may cause potential physiological changes in the fetus. ${ }^{[20]}$ Although there are inconsistent data about the relationship between 
the use of beta-blockers in pregnancy and the risk of fetal growth restriction, preterm birth, cardiac malformations, and perinatal mortality, there are some reports indicating that direct relationship could not be established due to methodological limitations in the interpretation of available data and presence of confounding factors. However, it is also reported that uncontrolled hypertension during pregnancy may increase the risk of maternal and fetal adverse events such as preeclampsia, premature birth, gestational diabetes, fetal growth restriction, and intrauterine demise. ${ }^{[21-25]}$

In the current study, amiodarone with concomitant medications was used in a pregnancy ended in miscarriage. Amiodarone and desethylamiodarone, its major metabolite, can cross the placenta and reach 9 to $14 \%$ of maternal serum concentrations in fetus. ${ }^{[25]}$ The available data are limited to identify the fetal risk related to amiodarone use in pregnancy. Amiodarone use during pregnancy may also increase the risk of neonatal hypothyroidism with or without goiter and predisposes to neonatal hyperthyroxinemia. It may be also associated with fetal bradycardia, long QT syndrome, ventricular septal defect, prematurity, and death. Amiodarone can be used during pregnancy, if the potential benefit to the mother justifies the possible risk to the fetus. Neonatal electrocardiogram and thyroid functions monitoring are also recommended. ${ }^{[25]}$

To the best of our knowledge, previous reports are usually limited to the use of CVMs alone during pregnancy, and are lacking the information regarding pregnancy outcomes related to their use with concomitant medications. Furthermore, other confounding factors that may affect pregnancy outcomes such as maternal age, smoking or alcohol use, radiation exposure, and chronic disease should be considered. Our relatively low sample size is the main limitation of this study. Although the number of the cases in this study is limited, our results may contribute to the literature. To achieve more accurate results, further large-scale, prospective studies are needed investigating specific CVMs groups.

In conclusion, based on our study results, it is not possible to establish a definite causality relationship between pregnancy outcomes and CVMs exposure. Nevertheless, we believe that the results of this study can contribute to the existing body of knowledge in this field and provide additional information to the physicians regarding the teratogenic risks of CVMs exposures during pregnancy.

\section{Declaration of conflicting interests}

The authors declared no conflicts of interest with respect to the authorship and/or publication of this article.

\section{Funding}

The authors received no financial support for the research and/or authorship of this article.

\section{REFERENCES}

1. Laopaiboon $\mathrm{M}$, Lumbiganon $\mathrm{P}$, Intarut $\mathrm{N}$, Mori $\mathrm{R}$, Ganchimeg T, Vogel JP, et al. Advanced maternal age and pregnancy outcomes: a multicountry assessment. BJOG 2014;121 Suppl 1:49-56.

2. Koren G, Pastuszak A, Ito S. Drugs in pregnancy. N Engl J Med. 1998;338:1128-37.

3. Bateman BT, Hernandez-Diaz S, Fischer MA, Seely EW, Ecker JL, Franklin JM, et al. Statins and congenital malformations: Cohort study. BMJ 2015;350:h1035.

4. Lewis G. Saving Mothers' Lives: The continuing benefits for maternal health from the United Kingdom (UK) Confidential Enquires into Maternal Deaths. Semin Perinatol 2012;36:19-26.

5. Clark SL, Belfort MA, Dildy GA, Herbst MA, Meyers JA, Hankins GD. Maternal death in the 21st century: Causes, prevention, and relationship to cesarean delivery. Am J Obstet Gynecol 2008;199:36.e1-5.

6. International Statistical Classification of Diseases and Related Health Problems 10th Revision (ICD-10) WHO Version for; 2016. Avaible from: https://www.who.int/ classifications/icd/icdonlineversions/en/ [Accessed: March 12, 2019]

7. Sedgh G, Singh S, Hussain R. Intended and unintended pregnancies worldwide in 2012 and recent trends. Stud Fam Plann 2014;45:301-14.

8. Bearak J, Popinchalk A, Alkema L, Sedgh G. Global, regional, and subregional trends in unintended pregnancy and its outcomes from 1990 to 2014: Estimates from a Bayesian hierarchical model. Lancet Glob Health 2018;6:e380-e389.

9. Newstead-Angel J, Gibson PS. Cardiac drug use in pregnancy: Safety, effectiveness and obstetric implications. Expert Rev Cardiovasc Ther 2009;7:1569-80.

10. Egen-Lappe V, Hasford J. Drug prescription in pregnancy: Analysis of a large statutory sickness fund population. Eur J Clin Pharmacol 2004;60:659-66.

11. Demir Ö, Arici MA, Demiral Y, Tunçok Y. Evaluation of drugs exposure in pregnancy according to different risk categories: Do FDA-based decisions lead to more curettage? Turkiye Klinikleri J Med Sci 2012;32:901-9.

12. Göker A, Kadığlu Duman M, Gürpınar T, Muci E, Yıldırım Y, Erköseoğlu İ, et al. Retrospective evaluation of the pregnant women consulted due to drug exposure during pregnancy. Turkiye Klinikleri J Gynecol Obst 2012;22:90-4. 
13. Lawn JE, Blencowe $\mathrm{H}$, Waiswa $\mathrm{P}$, Amouzou A, Mathers C, Hogan D, et al. Stillbirths: Rates, risk factors, and acceleration towards 2030. Lancet 2016;387:587-603.

14. Althabe F, Moore JL, Gibbons L, Berrueta M, Goudar SS, Chomba E, et al. Adverse maternal and perinatal outcomes in adolescent pregnancies: The Global Network's Maternal Newborn Health Registry study. Reprod Health 2015;12 Suppl 2(Suppl 2):S8.

15. Hauspurg A, Countouris ME, Jeyabalan A, Hubel CA, Roberts JM, Schwarz EB, et al. Risk of hypertension and abnormal biomarkers in the first year postpartum associated with hypertensive disorders of pregnancy among overweight and obese women. Pregnancy Hypertens. 2019;15:1-6.

16. Turner GM, Oakley CM, Dixon HG. Management of pregnancy complicated by hypertrophic obstructive cardiomyopathy. Br Med J 1968;4:281-4.

17. Bullock JL, Harris RE, Young R. Treatment of thyrotoxicosis during pregnancy with propranolol. Am J Obstet Gynecol 1975;121:242-5.

18. Langer A, Hung CT, Mc A'nulty JA, Harrigan JT, Washington E. Adrenergic blockade. A new approach to hyperthyroidism during pregnancy. Obstet Gynecol 1974;44:181-6.

19. Caton AR, Bell EM, Druschel CM, Werler MM, Lin AE, Browne ML, et al. Antihypertensive medication use during pregnancy and the risk of cardiovascular malformations. Hypertension 2009;54:63-70.
20. Davis RL, Eastman D, McPhillips H, Raebel MA, Andrade SE, Smith D, et al. Risks of congenital malformations and perinatal events among infants exposed to calcium channel and beta-blockers during pregnancy. Pharmacoepidemiol Drug Saf 2011;20:138-45.

21. Magee LA, Elran E, Bull SB, Logan A, Koren G. Risks and benefits of beta-receptor blockers for pregnancy hypertension: overview of the randomized trials. Eur J Obstet Gynecol Reprod Biol 2000;88:15-26.

22. Sibai BM, Gonzalez AR, Mabie WC, Moretti M. A comparison of labetalol plus hospitalization versus hospitalization alone in the management of preeclampsia remote from term. Obstet Gynecol 1987;70:323-7.

23. Lydakis C, Lip GY, Beevers M, Beevers DG. Atenolol and fetal growth in pregnancies complicated by hypertension. Am J Hypertens 1999;12:541-7.

24. Nakhai-Pour HR, Rey E, Bérard A. Antihypertensive medication use during pregnancy and the risk of major congenital malformations or small-for-gestationalage newborns. Birth Defects Res B Dev Reprod Toxicol 2010;89:147-54.

25. Abalos E, Duley L, Steyn DW, Henderson-Smart DJ. Antihypertensive drug therapy for mild to moderate hypertension during pregnancy. Cochrane Database Syst Rev 2007;(1):CD002252. 